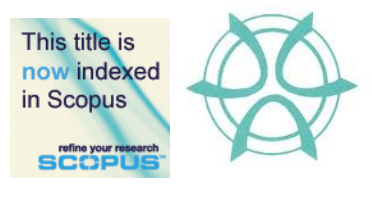

PLANNING MALAYSIA:

Journal of the Malaysian Institute of Planners

VOLUME 16 ISSUE 2 (2018), Page 12 - 20

\title{
PERCEPTION OF QUALITY OF LIFE AMONG COMMUNITY IN SELANGOR
}

\author{
Nur Farhanah Rosli ${ }^{1}$, Noor Suzilawati Rabe ${ }^{2} \&$ Mariana Mohamed \\ Osman $^{3}$ \\ ${ }^{1,2,3}$ Kulliyyah of Architecture and Environmental Design, \\ INTERNATIONAL ISLAMIC UNIVERSITY MALAYSIA
}

\begin{abstract}
The quality of life (QOL) is a subjective matter that has been diversely defined by scholars. Since 1930s researchers from various fields have expressed interests in the definition of QOL, including investigating and measuring QOL using different methods. Over the last four decades, Malaysia has made remarkable achievements regarding its economic growth as well as its socio-economic development. Numerous factors have been identified that may affect the quality of life of people according to their personal preferences. For example, the quality of the individual work as an engineer may differ with the quality of life of an individual work as a teacher. Nevertheless, how the individual itself measures the quality of life can be different between each other. Definitions of quality of life are as numerous and inconsistent as the methods of assessing it. This paper highlights the perception towards the quality of life for the community living in the state of Selangor. The objectives of this research are to identify the current living condition in Selangor and the level of satisfaction towards the living condition in the State. Data was obtaine through a questionnaire survey of 500 respondents living in Selangor. The outcome of the study indicates that the community in Selangor measured their quality of life differently based on their socio-economic background. Also, several indicators and action were highlighted by the community to be considered as part of the recommendation to improve the current living standard towards a better quality of life in Selangor.
\end{abstract}

Keywords: quality of life, quality, definition of quality 
PLANNING MALAYSIA

Journal of the Malaysia Institute of Planners (2018)

\section{INTRODUCTION}

Year by year, development in Malaysia has increased rapidly to make the country move forward in parallel with other developing and developed countries. As the word 'development' is underscored, it is not only based by the presence of the various skyscrapers, but also includes the efficiency of public transportation, housing development and the decreasing of problem in the community such as poverty. These developments that happened in Malaysia may affected the level of quality of life (QOL) for the residents in this country whether the affect comes in the form of negative or positive. QOL is an oft-quoted phrased used in various context with heterogenoues meaning (Nagchaudhuri, 1992). Quality of life is considered one of the most important dimension for sustaining any urban development (El Din, 2013). Different countries may gauge QOL by different concepts as they have different ways to undergo life and different problems to be tackled. Still, the basic elements of quality of life studied in each country are considered of similar essence or elements measuring quality of life.

\section{LITERATURE REVIEW}

The literature captures the similar essence of the meaning of the quality of life which it often becomes the argument and rising questions especially based on the measurement and definition to achieve the good quality of life. Quality of life always captures the notion of the meaning by the term itself. Since early 90's, the study of QOL has been explored. Diener and Suh (1997) is one of the early famous study of QOL that always being reffered to even presently. For example, can the quality of life be measured? If life's quality can be measured, what are aspects that can be included as the key measurement to find the answer of a range of quality of life in the certain area. Other than that, the elements to achieve a good quality of life are also becoming a discussion among scholars. Thus, many key indicator systems are bringing into the measures and the interpretation of well-being and also satisfaction.

Nagchaughuri (1992), and Bakar, Osman, Bachok, Zen and Abdullah (2017) said that the very first level of understanding, the concept of Quality of Life (QOL) is connected with psychological well being, which include the perception of health, adequate of nutritious food, shelter and adaptation to the environment including perception of the environment by each individual and group not only as resource but also as a resource of aesthetic satisfaction. However, in the year 2012, QOL refers to the day living enhanced by wholesome food and clean air and water, enjoyment of unfettered open spaces and water bodies, conservation of wildlife and natural resources, security from crime and others. The elements may be used to measure the energy and power a person owned that enable them to enjoy life (El Din, 2013).

In Malaysia context, QOL encompasses personal advancements, a healthy lifestyle, access and freedom to pursue knowledge, and attaining a 
Nur Farhanah Rosli, Noor Suzilawati Rabe \& Mariana Mohamed Osman

Perception of Quality of Life Among Community in Selangor

standard of living which surpasses the fulfillment of the basic and psychological needs of the individual, to achieve a level of social well-being compatible with the nation's aspirations. The meaning and identification of QOL by Economic lanning Unit mirror QOL definitions by certain scholars. QOL includes aspects of life that can affect our daily life and movement in life that concludes the life's quality of a certain individual.

\section{Quality of Life (QOL) Indicators}

To measure QOL, various indicators are needed to take into account. For example, Albouy, Godefroy and Lollivier (2012) identify 9 indicators to measure the QOL in European countries. The indicators include the social and economic well-being such as material living conditions, financial risks to which people are exposed, their health, their level of education, working conditions, involvement in public life, contacts with others, economic security and physical security.

Meanwhile, the Malaysia Quality of Life Index (MQLI) 1999 has 38 indicators categorized under 11 components of QOL. However, Malaysia WellBeing Index (MWI) 2012 also use several indicators include in both social and economic well-being.

Table 1: Malaysia Well-being Index, 2013

\begin{tabular}{lc}
\hline Components & Index \\
\hline Economic well-being & 136.9 \\
\hline Transport & 136.2 \\
Communications & 132.9 \\
Education & 131.8 \\
Income and Distribution & 128.6 \\
Working Life & \\
\hline Social well-being & 136.9 \\
\hline Housing & 131.4 \\
Leasure & 128.1 \\
Governance & 125.6 \\
Public safety & 120.6 \\
Social Participation & 120.3 \\
Culture & 114.1 \\
Health & 107.3 \\
Environment & 104.6 \\
Family & *base year: $2000=100$
\end{tabular}

The MWI measures the well-being of Malaysians from a multidimensional perspective. The index was formulated as a composite index using 14 components and 68 indicators. In this study, the performance of the MWI is complemented with a detailed analysis of the country's achievement in translating national income into well-being of Malaysians. Overall, the well- 
being of the Malaysians has improved with most of the indices moving positively with the change in national income.

\section{Policy and Thrust}

The national policy on environment has formulated to ensure the long term sustainability and improvement towards Quality of life. Bakar et al. (2017a, 2017b) mentioned that in order to improve quality of life, the basic amenities such as the access towards health facilities should be improved first.

In $11^{\text {th }}$ Malaysia Plan, there are several times the word 'quality of life' being mentioned. One of the 11th Malaysia Plan objectives are to achieve good quality of life and sustainable well-being in by enhancing the economy of individual and create opportunity for these people in order to achieve good quality of life (Bakar et.al, 2017c). The Malaysia Plan also ensures more equitable access to the economic growth opportunity will increasing the wellbeing and quality of life by the communities. The six thrusts of the plan include the improving wellbeing for all Malaysian. The Government has always adopted a balanced development approach that gives equal emphasis to both economic growths and the community well-being. The well-being discusses about the standard of living and the quality of life of the community. The standard of living includes the individual's socio-economic, physical and psychological needs (Bakar, Osman, Bachok, Zen, \& Abdullah, 2017). The Government will improve the well-being of Malaysians including the socio-economic and geographic background of the community.

The next thrust that mention about the improving quality of life of Malaysian include the pursuing green growth for sustainability and resilience. The green growth refers to the growth that is resource efficient, clean and resilient. This strategy will lead to the better quality of growth, strengthened food, water and energy security, lower environment risks and ecological scarcities, and be better in well-being and quality of life.

\section{METHODOLOGY}

In this research, the method used is a quantitative method. Quantitative method is used to emphasize objective measurements and the statistical, mathematical or numerical analysis that can be transformed into a usable statistic. The quantitative design is a research design attempt to maximize objective, replicability as well as the generality of findings. As this study focusses on assessment of the quality of life among communities in the urban area in Selangor, the key for the study is to the use of instruments such as survey to collect data. In addition, the survey method used include questionnaire that comprises numerous factors and elements of QOL mentioned by the community.

Likert scale of $0-10$ is used in order to answer the questionnaire survey. The study will be focusing on selected quality of life's indicators which are 
Nur Farhanah Rosli, Noor Suzilawati Rabe \& Mariana Mohamed Osman

Perception of Quality of Life Among Community in Selangor

economic capacity, transportation, living condition, environment, social involvement, public safety, health and physical well-being, daily activities, as well as educational background. Each of the elements consists of certain questions which will be mark by the respondents using Likert scale that has been provided The study focusing on 500 residents lives in the developed state in Malaysia namely Selangor. The convenient sampling method is used as it is the easiest to recruit subject for the study and to find the respondents for the study. The study attempts to analyse the results by using Relative Importance Index (RII) and correlation.

\section{FINDINGS AND DISCUSSION}

500 respondents living in Selangor were selected. They were inquired on the nine main indicators selected for the study. Respondents selected are between the ages of 18- 75 years old. The respondents came from various demographic background and characteristics which makes the sampling randomly represent the population in Selangor.

Table 2: Respondents' profile

\begin{tabular}{lc}
\hline Respondents profile & Percentage (\%) \\
\hline Age & \\
\hline 20 \& below & 0.60 \\
21-30 years old & $\mathbf{4 4 . 8 0}$ \\
31-40 years old & 35.40 \\
41-50 years old & 11.40 \\
51-60 years old & 5.40 \\
61-70 years old & 1.60 \\
71 and above & 0.80 \\
\hline Educational level & \\
\hline Primary School & 2.2 \\
Secondary School & 23.6 \\
STPM/Certificate/ & 31.0 \\
Diploma & $\mathbf{3 7 . 4}$ \\
Degree & 4.6 \\
Master & 1.2 \\
PhD & \\
\hline Number of household & 10.4 \\
\hline 1 & 11.2 \\
2 & $\mathbf{2 4 . 2}$ \\
$\mathbf{3}$ & 22.2 \\
5 & 17.4 \\
6 & 9.6 \\
7 & 2.6 \\
8 & 2.2
\end{tabular}




\begin{tabular}{lc}
9 & 0.2 \\
\hline Range of household income & \\
\hline 1,000 and Below & 2.2 \\
$1,001-2,000$ & 18.0 \\
$\mathbf{2 , 0 0 1 - 3 , 0 0 0}$ & $\mathbf{2 2 . 8}$ \\
$3,001-4,000$ & 10.8 \\
$4,001-5,000$ & 11.4 \\
$5,001-6,000$ & 10.6 \\
$6,001-7,000$ & 7.2 \\
$7,001-8,000$ & 5.0 \\
$8,001-9,000$ & 2.0 \\
$9,001-10,000$ & 4.0 \\
10,000 and above & 6.0 \\
\hline
\end{tabular}

Table 2 shows the respondents' educational background. Majority of the respondents comes from the age range of 21-30 years old (44.8\%). This age range can be considered as within the productive working age. Most of the respondents had bachelor degree (37.4\%) as the highest education level followed by STPM/ Certificate and Diploma (31.0\%). Most of the respondents reportedly had monthly household income between RM 2,001 and 3,000. Majority of the respondents had household size of three persons $(24.2 \%)$.

In this study, the QOL indicators include the elements inside social and economic well-being. QOL in this study are based on the primary data collected from the field survey and measured using Relative Importance Index (RII). The method to calculate RII is:

$$
\mathrm{RII}=\frac{\sum W}{A * N}
$$

$\mathrm{W}=$ weight given to each statement by respondents and range from $0-10$

$\mathrm{A}=$ Higher respondents' integer

$\mathrm{N}=$ Total number of respondents

By using the equation above, the result of RII was ranked to identify the most important indicator answer by the 500 selected respondents around Selangor area. The higher values of index indicate higher QOL chosen by the respondents.

Table 3: RII index based on the QOL components

\begin{tabular}{lcc}
\hline Components & RII & Rank \\
\hline 1) Economic capacity & & \\
Satisfaction household income & 0.616 & 2 \\
Job satisfaction & 0.662 & 1 \\
Monthly income sufficiency & 0.591 & 4
\end{tabular}


Nur Farhanah Rosli, Noor Suzilawati Rabe \& Mariana Mohamed Osman

Perception of Quality of Life Among Community in Selangor

$\begin{array}{lll}\text { No problem of commuting cost } & 0.608 & 3\end{array}$

No problem to buy properties

0.39

2) Transportation

Own transportation

$0.841 \quad 1$

Usage of public transportation

$0.38 \quad 2$

Public transportation preferable

$0.359 \quad 3$

3) Living condition

Satisfaction of living place

$\begin{array}{ll}0.739 & 1\end{array}$

Neighbouring with foreigners

$0.551 \quad 3$

Strategic house location

0.737

Adequate of PWDs facilities

0.411

2

4) Environment

Air quality

$0.722 \quad 2$

Water quality and provision

0.749

Crowding and noise level

$0.657 \quad 4$

Protection and preservation of natural element

0.637

0.644

Overall landscape

0.715

5) Social involvement

Social interaction with residents of neighbourhood

0.627

0.630

0.664

Interracial relations

$0.664-1$

Involvement in club/association in neighbourhood/work

place

$0.527 \quad 5$

Overall satisfaction with social interaction

0.59

4

6) Public safety

Safety walking alone in day time

0.787

0.653

0.674

24 hours of Police availabity

0.654

24hours of fire bridges availability

0.746

Overall satisfaction of safety conditions

0.723

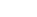

(1)

3

\section{7) Health \& Physical well-being}

Satisfaction of health condition

$0.841 \quad 1$

Energetic to woke up every morning

0.782

Monthly, weekly, daily check-up

0.485

0.738

0.806

Perform daily activities

0.721

0.811

1

Never have unstable mood

0.579

0.399

0.635

0.476

1
6
4
5
2
3

\section{8) Daily activities}

Plan daily activities

Record daily activities

1
4

Plan activities a week beforehand 
PLANNING MALAYSIA

Journal of the Malaysia Institute of Planners (2018)

\begin{tabular}{lcc}
\hline Plan activities a month beforehand & 0.446 & 4 \\
\hline 9) Education & & \\
Satisfaction with current educational background & 0.710 & 2 \\
Wish to continue study & 0.608 & 4 \\
Supportive if family members want to further study & 0.919 & 1 \\
Malaysia educational system generate ideas of students & 0.685 & 3 \\
\hline Overall satisfaction & & \\
In general, how much do you enjoying your life? & 0.772 & 1 \\
Overall, how would you rate your quality of life & 0.744 & 2 \\
\hline
\end{tabular}

Overall, the highest RII index noted by the result is 0.919 (education) which was supports from family members to continue study. Contratily, the lowest RII index, 0.359, fell under the transportation indicators (public transport preferable by the respondents).

For QOL aspects of economic capacity, the highest RII index was job satisfaction (RII $=0.662)$ while the lowest RII index was no problem to buy properties $(\mathrm{RII}=0.39)$. Even though the respondents were satisfied with their job, they still had problem in buying properties for either themselves or for their family. As for the transportation aspects, most of the respondents own private transports (RII $=0.841)$ which discouraged them from using the public transport.

Living condition aspect result that satisfaction of living condition result as the highest index (RII=0.739). As for the air quality, most of the respondents were satisfied with the air quality around their living place (RII=0.722). Majority of the respondents feel safe to walk alone during day time. Additionally, majority of the respondents satisfied with their health condition (RII=0.841).

Majority of the respondents claim to have enjoyed their life (RII=0.772) ( $\mathrm{RII}=0.744)$. Generally, each of the elements inside the QOL indicators such as economic capacity, transportation, living condition, environment, social involvement, public safety, health and physical well-being, daily activities as well as education, affect one's life and the QOL of the individual.

It can be assumed that the QOL indicators are interrelated with each other. These include indicators such as the satisfaction towards household income, job positions, vehicle ownership and living place.

The perception of the 500 respondents in Selangor relate to the 11th Malaysia Plan thrusts. The objectives of the thrust is to achieve good QOL and to improve the QOL especially in the psychological, social well-being and physical needed.

\section{CONCLUSION}

In a nutshell, the nine indicators of QOL were important aspects influencing one's life. Every aspect of the development gives impacts either positive or negatives towards the communities residing inside the developing areas as well as the 
Nur Farhanah Rosli, Noor Suzilawati Rabe \& Mariana Mohamed Osman

Perception of Quality of Life Among Community in Selangor

surrounding areas. The impact of development need to be studied before pursuing the development projects.

\section{REFERENCES}

Albouy, V., Godefroy, P., \& Lollivier, S. (2012). Measuring quality of life. Retrieved from https://www.insee.fr/en/statistiques.

Bakar, A. A., Osman, M. M., Bachok, S., Ibrahim, I., \& Abdullah, A. (2017a) Sustainable well-being: An empirical exploration on human interdependence with other humans. Advanced Science Letters, 23(7), 6357-6361.

Bakar, A. A., Osman, M. M., Bachok, S., Ibrahim, I., \& Abdullah, A. (2017b). Sustainable well-being: An empirical exploration on human interdependence with the environment. Advanced Science Letters, 23(7), 6352-6356.

Bakar, A. A., Osman, M. M., Bachok, S., Ibrahim, I., \& Abdullah, A. (2017c). Assessment on subjective sustainable well-being for central region of Malaysia. Advanced Science Letters, 23(4), 2929-2933.

Bakar, A. A., Osman, M. M., Bachok, S., Zen, I., \& Abdullah, A. (2017). A theoretical assessment on sustainable wellbeing indicators for people interrelationships. Planning Malaysia, 15(1), 21-30.

Bakar, A. A., Osman, M. M., Bachok, S., Zen, I., \& Abdullah, M. F. (2017) A review on sustainable wellbeing indicators for human interrelationships with the environment. Planning Malaysia, 15(1), 357-368.

El Din, H. S. (2013). Principles of urban quality of life for a neighborhood. $H B R C$ Journal, 9(1), 86-92.

Nagchaudhuri, B. D. (1992). The quality of life. India: Indian Institute of Advance Study 